\title{
Sensitivity of International Classification of Diseases codes for hyponatremia among commercially insured outpatients in the United States
}

\author{
Alisa M Shea ${ }^{1}$, Lesley H Curtis*1,3, Lynda A Szczech ${ }^{2,4}$ and \\ Kevin A Schulman ${ }^{1,3}$
}

\begin{abstract}
Address: ${ }^{1}$ Center for Clinical and Genetic Economics, Duke Clinical Research Institute, PO Box 17969, Durham, North Carolina, USA, ${ }^{2}$ Duke Clinical Research Institute, Durham, North Carolina, USA, ${ }^{3}$ Division of General Internal Medicine, Department of Medicine, Duke University School of Medicine, Durham, North Carolina, USA and ${ }^{4}$ Division of Nephrology, Department of Medicine, Duke University School of Medicine, Durham, North Carolina, USA
\end{abstract}

Email: Alisa M Shea - alisa.shea@duke.edu; Lesley H Curtis* - lesley.curtis@duke.edu; Lynda A Szczech - szcze001@mc.duke.edu; Kevin A Schulman - kevin.schulman@duke.edu

* Corresponding author

Published: 18 June 2008

BMC Nephrology 2008, 9:5 doi:10.1186/147/-2369-9-5

This article is available from: http://www.biomedcentral.com/I47|-2369/9/5

(c) 2008 Shea et al; licensee BioMed Central Ltd.

This is an Open Access article distributed under the terms of the Creative Commons Attribution License (http://creativecommons.org/licenses/by/2.0), which permits unrestricted use, distribution, and reproduction in any medium, provided the original work is properly cited.

\begin{abstract}
Background: Administrative claims are a rich source of information for epidemiological and health services research; however, the ability to accurately capture specific diseases or complications using claims data has been debated. In this study, the authors examined the validity of International Classification of Diseases, Ninth Revision, Clinical Modification (ICD-9-CM) diagnosis codes for the identification of hyponatremia in an outpatient managed care population.
\end{abstract}

Methods: We analyzed outpatient laboratory and professional claims for patients aged 18 years and older in the National Managed Care Benchmark Database from Integrated Healthcare Information Services. We obtained all claims for outpatient serum sodium laboratory tests performed in 2004 and 2005, and all outpatient professional claims with a primary or secondary ICD-9-CM diagnosis code of hyponatremia (276.I).

Results: A total of 40,668 outpatient serum sodium laboratory results were identified as hyponatremic (serum sodium < $136 \mathrm{mmol} / \mathrm{L}$ ). The sensitivity of ICD-9-CM codes for hyponatremia in outpatient professional claims within 15 days before or after the laboratory date was $3.5 \%$. Even for severe cases (serum sodium $\leq 125 \mathrm{mmol} / \mathrm{L}$ ), sensitivity was $<30 \%$. Specificity was $>99 \%$ for all cutoff points.

Conclusion: ICD-9-CM codes in administrative data are insufficient to identify hyponatremia in an outpatient population.

\section{Background}

Hyponatremia, defined as an abnormally low level of serum sodium, is the most frequently observed electrolyte disorder in the United States and is associated with signif- icant morbidity and mortality in patients with heart failure $[1,2]$, myocardial infarction $[3,4]$, and liver cirrhosis $[5,6]$, as well as in the hospitalized elderly population at large [7]. Among general acute care patients, the preva- 
lence of hyponatremia is estimated to be approximately $1 \%[8,9]$. However, much higher rates-ranging from $18 \%$ to $30 \%$-have been observed among elderly nursing home residents [10] and in intensive care settings [11]. Little is known about the prevalence of hyponatremia in outpatient settings or in the general population.

Administrative claims data are a rich source of information for epidemiological and health services research. With increasing frequency, researchers are turning to administrative claims data to ascertain information about patient outcomes and hospital quality [12-19]. However, the ability to accurately capture specific diseases or complications using claims data has been a subject of considerable debate [20-24].

Most validation studies of diagnosis and procedure codes have relied on retrospective chart review as the source of comparative information. Using medical record review as the gold standard, Quan et al [25] found that the validity of International Classification of Diseases, Ninth Revision, Clinical Modification (ICD-9-CM) codes for invasive or major surgical procedures in inpatient discharge claims was high; however, codes for routine procedures were often inaccurate or incomplete. Geraci et al [26] used the same method to assess the validity of 30 ICD-9-CM codes for common in-hospital complications as observed in patient discharge records from nine hospitals. They found an overall sensitivity of $34 \%$ and a positive predictive value of $32 \%$. A handful of studies have used laboratory information to validate administrative claims codes. Wei and Walsh [27] compared managed care claims data with laboratory results and found that less than $25 \%$ of female beneficiaries with a positive test for chlamydia were coded as such. In another study, researchers used clinical, radiological, and laboratory data to assess the validity of ICD-9 codes for the diagnosis of gout in an ambulatory managed care population and found a positive predictive value of $61 \%[28]$.

To our knowledge, there has been only one published study of the validity of ICD-9-CM codes for the diagnosis of hyponatremia. Movig et al [29] compared inpatient hospital discharge records with inpatient laboratory data and reported a sensitivity of $30 \%$ for even the strictest definition of hyponatremia $(\leq 115 \mathrm{mmol} / \mathrm{L})$. Positive predictive value for laboratory results showing serum sodium $\leq$ $135 \mathrm{mmol} / \mathrm{L}$ was $91.7 \%$. The study did not address the validity of coding for hyponatremia outside the inpatient setting. Therefore, we sought to examine the validity of ICD-9-CM diagnosis codes for the identification of hyponatremia in an outpatient managed care population.

\section{Methods}

\section{Data source}

We used data from the National Managed Care Benchmark Database from Integrated Healthcare Information Services (IHCIS; Waltham, MA). The database includes complete medical and eligibility data from over 30 health plans covering more than 25 million lives in the United States. Outpatient laboratory data are available for approximately $10 \%$ of members, and outpatient pharmacy information is available for $90 \%$ of members. Laboratory tests performed during inpatient hospitalizations are not collected in the database. To protect member confidentiality, IHCIS removed all direct identifiers.

\section{Claim identification}

We limited the analysis to claims filed in 2004 and 2005 for members aged 18 years and older. We obtained all claims for outpatient serum sodium laboratory tests performed between January 1, 2004, and December 31, 2005. Serum sodium values $<8 \mathrm{mmol} / \mathrm{L}$ were excluded ( $\mathrm{n}$ $=1854$ ) because these were considered data errors. All remaining values were $\geq 100 \mathrm{mmol} / \mathrm{L}$. When multiple serum sodium tests were performed on the same day, we retained the highest value for the analysis. We also obtained all outpatient professional claims incurred in 2004 and 2005 with a primary or secondary ICD-9-CM diagnosis code of hyponatremia (276.1).

For each claim, members were required to have had continuous eligibility for at least 60 days before and 15 days after the claim date of service. Because this database represents a transient managed care population with a great deal of movement into and out of plans, we chose a 60day period of observation prior to the serum sodium laboratory test so that we might still observe comorbid claims but not reduce the study population substantially by requiring a lengthy period of pretest eligibility. Multiple successive periods of eligibility, defined as an observed coverage end date followed immediately by a new coverage start date, were considered switches in insurance product and not a discontinuation of coverage; therefore, such changes were not considered an interruption in coverage but rather a single, continuous period of eligibility.

We excluded members with a professional claim for dialysis in 2004 or 2005 . We also excluded members with serum/plasma triglycerides $>400 \mathrm{mg} / \mathrm{dL}$ as measured 15 days before or after the reference serum sodium date, due to the possibility that any observed changes in serum sodium were related to pseudohyponatremia. If blood glucose was $>300 \mathrm{mg} / \mathrm{dL}$ as measured 15 days before or after the reference serum sodium lab date, we adjusted the serum sodium laboratory result by a factor of 1.6 $($ adjusted value $=$ original value $+([$ glucose -100$] / 100) \times$ 1.6) [30]. 
We reviewed inpatient, outpatient, and professional claims for evidence of underlying comorbid conditions within the 60-day period before through 15 days after the reference serum sodium date. Specifically, we searched for evidence of liver cirrhosis (ICD-9-CM code 572.4); congestive heart failure (428.0); nephritis, nephrotic syndrome, and nephrosis (580-589); and syndrome of inappropriate secretion of antidiuretic hormone (253.6). In addition, we identified comorbid conditions using the coding algorithms described by Birman-Deych et al [31] and Quan et al [32]. We searched all inpatient, outpatient, and professional claims for 60 days before through 15 days after the reference serum sodium date for evidence of cerebrovascular disease (362.34, 430.x-438.x), chronic obstructive pulmonary disease $(416.8,416.9,490 . x-$ 505.x, 506.4, 508.1, 508.8), coronary heart disease (410.x-414.x, 429.2, V45.81), dementia (290.x, 294.1, 331.2), diabetes mellitus (250.x), hypertension (401.x405.x, 437.2), kidney disease (403.01, 403.11, 403.91, 404.02, 404.036, 404.12, 404.13, 404.92, 404.93, 582.x, 583.0-583.7, 585.x, 586.x, 588.0, V42.0, V45.1, V56.x), metastatic carcinoma (196.x-199.x), peripheral vascular disease (093.0 437.3, 440.x, 441.x, 443.1-443.9, 47.1, $557.1,557.9, \mathrm{~V} 43.4$ ), and rheumatic disease (446.5, 710.0-710.4, 714.0-714.2, 714.8, 725.x).

We also identified outpatient pharmacy claims for medications known to cause hyponatremia. We used National Drug Codes to identify claims for phenothiazines, selective serotonin reuptake inhibitors, thiazide diuretics, tricyclic antidepressants, prostaglandin synthesis inhibitors, desmopressin, oxytocin, opiate derivatives, chlorpropamide, clofibrate, carbamazepine, cyclophosphamide, or vincristine incurred 60 days before through 15 days after each outpatient serum sodium laboratory date [33].

Finally, for each member with an eligible outpatient serum sodium laboratory claim, we obtained all outpatient professional claims from 2004 or 2005 that did not include an ICD-9-CM diagnosis code for hyponatremia.

\section{Statistical analysis}

We defined hyponatremia as serum sodium $<136 \mathrm{mmol} /$ $\mathrm{L}[1,2,4,33-35]$; however, we also performed validity analyses on three additional strata: serum sodium $\leq 133$ $\mathrm{mmol} / \mathrm{L} ; \leq 130 \mathrm{mmol} / \mathrm{L} ;$ and $\leq 125 \mathrm{mmol} / \mathrm{L}$. We used basic descriptive statistics to summarize demographic characteristics, comorbidities, and prescription drug claim information for members with serum sodium values indicating hyponatremia both with and without a corresponding outpatient professional claim for hyponatremia. We assessed differences between groups using $\chi^{2}$ tests for categorical variables and Wilcoxon rank sum tests for continuous variables.
For all measurements of validity, we considered the laboratory result to be the gold standard of diagnosis and the outpatient professional claim to be the test. We defined sensitivity as the probability of a positive test-an outpatient professional claim with a primary or secondary ICD9-CM diagnosis code of hyponatremia observed within 15 days before or after a serum sodium laboratory result indicating hyponatremia. We defined specificity as the probability of a negative test-an outpatient professional claim that did not include an ICD-9-CM code for hyponatremia or the absence of any outpatient professional claim within 15 days before or after a serum sodium laboratory result not indicating hyponatremia. Positive predictive value was the probability of a laboratory result indicating hyponatremia among positive outpatient professional claims; negative predictive value was the probability of a laboratory result not indicating hyponatremia among negative outpatient professional claims or in the absence of any outpatient claim.

Using all serum sodium laboratory claims indicating hyponatremia, we performed logistic regression analysis to explore the relationships between undocumented hyponatremia (serum sodium laboratory claim indicating hyponatremia, but no professional ICD-9-CM claim for hyponatremia) and members' demographic characteristics and comorbidities as observed within 60 days before through 15 days after the laboratory encounter.

We used SAS version 9.1.5 for all analyses (SAS Institute Inc, Cary, NC). The institutional review board of the Duke University Health System approved this study.

\section{Results}

There were 1,901,254 eligible serum sodium laboratory claims in the study sample. Of these, 40,668 (2.1\%) indicated hyponatremia (serum sodium $<136 \mathrm{mmol} / \mathrm{L}$ ). Outpatient professional claims with an ICD-9-CM diagnosis code for hyponatremia were observed within 15 days before or after the hyponatremic serum sodium lab date for 1407 of these claims (3.5\%) (Table 1).

Mean age of members at the time of the laboratory claim indicating hyponatremia was 59 years, and over half of all claims were for women (61\%). Hypertension was the most commonly identified comorbidity in this sample. Evidence of hypertension during the 60-day period preceding the laboratory claim date was present for $36.5 \%$ of claims. Diabetes $(20.5 \%)$, coronary heart disease $(14.4 \%)$, and chronic obstructive pulmonary disease $(10.5 \%)$ were also observed more frequently than other conditions. Outpatient pharmacy claims for medications known to cause hyponatremia were observed within the 60/+15-day period before or after the laboratory date in 1 of every 4 claims (Table 1 ). 
Table I: Sample characteristics*

\begin{tabular}{|c|c|c|c|c|}
\hline \multirow[t]{2}{*}{ Characteristic } & \multicolumn{3}{|c|}{ Laboratory Claims Indicating Hyponatremia $\dagger$} & \multirow[t]{2}{*}{$p \|$} \\
\hline & All Claims $(n=40,668)$ & Negative Test $\ddagger(n=39,261)$ & Positive Test $\S(n=1407)$ & \\
\hline Age, mean (SD), y & $59(15.7)$ & $59(15.7)$ & $67(12.3)$ & $<0.001$ \\
\hline Female sex & $24,694(60.7)$ & $23,769(60.5)$ & 925 (65.7) & $<0.001$ \\
\hline \multicolumn{5}{|l|}{ Underlying conditions and comorbidities } \\
\hline Cerebrovascular disease & $1874(4.6)$ & $|72|(4.4)$ & $153(10.9)$ & $<0.001$ \\
\hline Chronic obstructive pulmonary disease & $4279(10.5)$ & $4020(10.2)$ & $259(18.4)$ & $<0.001$ \\
\hline Congestive heart failure & $2742(6.7)$ & $2605(6.6)$ & $137(9.7)$ & $<0.001$ \\
\hline Coronary heart disease & $5857(14.4)$ & $5560(14.2)$ & $297(2 I . I)$ & $<0.001$ \\
\hline Dementia & $164(4.0)$ & $|4|(3.5)$ & $23(1.6)$ & $<0.001$ \\
\hline Diabetes mellitus & $8342(20.5)$ & $8102(20.6)$ & $240(17.1)$ & 0.001 \\
\hline Hypertension & $14,825(36.5)$ & 13,997 (35.7) & $828(58.8)$ & $<0.001$ \\
\hline Kidney disease & $149 \mid(3.7)$ & $1405(3.6)$ & $86(6.1)$ & $<0.001$ \\
\hline Liver cirrhosis & $26(0.1)$ & $24(0.1)$ & $2(0.1)$ & 0.24 \\
\hline Metastatic carcinoma & $2325(5.7)$ & $2246(5.7)$ & $79(5.6)$ & 0.87 \\
\hline Nephritis, nephrotic syndrome, and nephrosis & $1918(4.7)$ & $1800(4.6)$ & $118(8.4)$ & $<0.001$ \\
\hline Peripheral vascular disease & $1613(4.0)$ & $1546(3.9)$ & $67(4.8)$ & 0.12 \\
\hline Rheumatic disease & $129 \mid(3.2)$ & $1254(3.2)$ & $37(2.6)$ & 0.24 \\
\hline Syndrome of inappropriate antidiuretic hormone & $157(3.9)$ & $91(2.3)$ & $66(4.7)$ & $<0.001$ \\
\hline Medications known to cause hyponatremia & $10,492(25.8)$ & $10,144(25.8)$ & $348(24.7)$ & 0.35 \\
\hline
\end{tabular}

* Values are expressed as number (percentage) unless otherwise indicated.

† Hyponatremia was defined as serum sodium $<136 \mathrm{mmol} / \mathrm{L}$.

¥ A negative test was defined as the presence of an outpatient professional claim with no ICD-9-CM code for hyponatremia or the absence of any outpatient professional claims within 15 days before or after the laboratory claim indicating hyponatremia.

$\S A$ positive test was defined as the presence of an outpatient professional claim with a primary or secondary ICD-9-CM diagnosis code of hyponatremia observed within 15 days before or after the laboratory claim indicating hyponatremia.

II $p$-Values for the comparison between the positive and negative test groups.

Compared to claims without a corresponding diagnosis code, mean age was greater among outpatient laboratory claims indicating hyponatremia with an outpatient professional diagnosis code for hyponatremia observed within 15 days (positive test, 67 versus 59 years; $p<.001$ ), and claims were observed significantly more often for women $(61 \%$ versus $66 \%$; $p=<.001)$. Evidence of hypertension was observed nearly twice as often during the period preceding a laboratory claim with a positive test than for claims with a negative test or with no temporally adjacent outpatient professional claims (59\% versus 36\%; $p<.001)$. Compared to claims that did not have a diagnosis code for hyponatremia, claims with a positive test were also significantly more likely to be observed for members diagnosed with kidney disease, cardiovascular conditions, and/or chronic obstructive pulmonary disease; however, claims with a positive test were significantly less likely to be observed among members with diabetes or dementia (Table 1).

Sensitivity for hyponatremia defined as serum sodium < $136 \mathrm{mmol} / \mathrm{L}$ was $3.5 \%$; specificity was greater than $99 \%$. Positive predictive value was $63 \%$, and negative predictive value was $98 \%$ (Table 2 ). Sensitivity values for the $\leq 133$ $\mathrm{mmol} / \mathrm{L}, \leq 130 \mathrm{mmol} / \mathrm{L}$, and $\leq 125 \mathrm{mmol} / \mathrm{L}$ strata were
$7.5 \%, 13.9 \%$, and $29.6 \%$, respectively. Specificity was greater than $99 \%$ for all of the alternative cutoff points (Table 3).

In the multivariable analysis exploring the relationships between undocumented hyponatremia and member demographic characteristics and comorbidities, laboratory results indicating hyponatremia among older members were significantly more likely to have a corresponding outpatient professional claim than those observed for younger members. Controlling for other comorbid diagnoses, medications known to cause hyponatremia, and sex, an increase of 10 years in age was associated with an almost 30\% drop in the likelihood of

Table 2: Relationship between ICD-9-CM code documentation and laboratory serum sodium $<136 \mathrm{mmol} / \mathrm{L}$

\begin{tabular}{cccc}
\hline & \multicolumn{3}{c}{ Hyponatremia } \\
ICD-9=276.1 & + & 1407 & - \\
& - & 39,261 & 839 \\
& & & $1,859,747$ \\
\hline
\end{tabular}

Sensitivity $=3.46 \%$

Specificity $=99.95 \%$

Positive predictive value $=62.64 \%$

Negative predictive value $=97.93 \%$ 
Table 3: Validity measures by laboratory serum sodium values

\begin{tabular}{lrrrr}
\hline & \multicolumn{4}{c}{ Serum Sodium (mmol/L) } \\
\cline { 2 - 5 } & $<136$ & $\leq 133$ & $\leq 130$ & $\leq 125$ \\
\hline Sensitivity & 3.46 & 7.50 & 13.85 & 29.57 \\
$\quad$ False-negative rate & 96.54 & 92.50 & 86.15 & 70.43 \\
Specificity & 99.95 & 99.94 & 99.92 & 99.90 \\
$\quad$ False-positive rate & 0.05 & 0.06 & 0.08 & 0.10 \\
Positive predictive value & 62.64 & 48.74 & 30.00 & 10.42 \\
Negative predictive value & 97.93 & 99.28 & 99.78 & 99.97 \\
\hline
\end{tabular}

a negative claim or no claim at all (odds ratio: 0.74; 95\% confidence interval: 0.66, 0.74; data not shown). Laboratory claims preceded by a comorbid diagnosis of cerebrovascular disease, chronic obstructive pulmonary disease, hypertension, dementia, nephritis/nephrosis, or syndrome of inappropriate antidiuretic hormone were also less likely to be undocumented by a diagnosis code on an outpatient professional claim. Laboratory claims preceded by a comorbid diagnosis of diabetes or peripheral vascular disease were significantly more likely to be undocumented by a diagnosis code. Claims for medications known to cause hyponatremia did not have a significant impact on ICD-9-CM documentation of laboratoryidentified hyponatremia (Table 4).

\section{Discussion}

We examined the validity of ICD-9-CM diagnosis codes for the identification of hyponatremia in an outpatient managed care population using data from the IHCIS National Managed Care Benchmark Database. Our results show that while the ICD-9-CM code for hyponatremia is highly specific in outpatient claims, its sensitivity is extremely low. Even for the most severe cases (serum sodium $\leq 125 \mathrm{mmol} / \mathrm{L}$ ), we found sensitivity to be less than $30 \%$. Similarly, the positive predictive value of an outpatient professional claim for hyponatremia was only $63 \%$ using the least strict serum sodium measurement (< $136 \mathrm{mmol} / \mathrm{L}$ ). These findings are consistent with an earlier study by Movig et al [29], which showed low sensitivity for the coding of hyponatremia in inpatient settings, although the positive predictive value of ICD-9-CM codes in outpatient claims in our study was significantly less than the corresponding inpatient rates found in the previous study.

These low rates of coding for hyponatremia may be largely due to the ICD-9-CM diagnostic coding and reporting guidelines for outpatient services. According to these guidelines, only conditions that "require or affect patient care treatment or management" should be documented. Moreover, "related signs and symptoms" should not be coded when a more definitive diagnosis is known [36]. Thus, at mildly decreased levels requiring no medical intervention and/or in the presence of causal underlying disease such as syndrome of inappropriate antidiuretic hormone or liver cirrhosis, it may be inappropriate to code for hyponatremia on an outpatient claim. Similarly, there may be limited space available for diagnoses on the

Table 4: Likelihood of a negative test for claims indicating hyponatremia*

\begin{tabular}{lcc}
\hline & $\mathrm{OR}$ & $95 \% \mathrm{Cl}$ \\
\hline Age in years & 0.97 & $0.96,0.97$ \\
Female & 0.75 & $0.67,0.85$ \\
Underlying conditions and comorbidities & 0.61 & $0.50,0.73$ \\
$\quad$ Cerebrovascular disease & 0.62 & $0.54,0.72$ \\
Chronic obstructive pulmonary disease & 1.09 & $0.89,1.34$ \\
Congestive heart failure & 0.98 & $0.84,1.14$ \\
Coronary heart disease & 0.44 & $0.27,0.70$ \\
Dementia & 1.47 & $1.27,1.70$ \\
Diabetes mellitus & 0.53 & $0.47,0.59$ \\
Hypertension & 1.24 & $0.84,1.83$ \\
$\quad$ Kidney disease & 0.31 & $0.07,1.38$ \\
$\quad$ Liver cirrhosis $\dagger$ & 1.11 & $0.87,1.41$ \\
Metastatic carcinoma & 0.49 & $0.35,0.69$ \\
$\quad$ Nephritis, nephrotic syndrome, and nephrosis & 1.40 & $1.08,1.82$ \\
Peripheral vascular disease & 1.27 & $0.91,1.77$ \\
Rheumatic disease & 0.06 & $0.04,0.08$ \\
$\quad$ Syndrome of inappropriate antidiuretic hormone & 1.08 \\
Medications known to cause hyponatremia & $0.95,1.22$ \\
\hline
\end{tabular}

* Hyponatremia was defined as serum sodium $<136 \mathrm{mmol} / \mathrm{L}$. A negative test was defined as the presence of an outpatient professional claim with no ICD-9-CM code for hyponatremia or the absence of any outpatient professional claims within 15 days before or after the laboratory claim indicating hyponatremia.

t Indicates that the condition was present in $<1 \%$ of the population.

Abbreviations: OR indicates odds ratio; and $\mathrm{Cl}$, confidence interval. 
outpatient claim form. The IHCIS database, for example, allows for a maximum of 3 diagnosis codes on each professional claim record. As shown in Table 1, hyponatremia is often seen in the presence of other significant comorbidities. Given that ICD-9-CM coding guidelines also specify that one should "list first the ICD-9-CM code for the diagnosis, condition, problem, or other reason for encounter/visit shown in the medical record to be chiefly responsible for the services provided" [36], other conditions may have taken precedence on the claim form.

The clinical consequences of even mild hyponatremia are well-documented [3,4,6,34,35,37-39]. In a cohort of elderly patients, hyponatremia at hospital admission was a significant independent predictor of mortality after adjustment for age, sex, length of stay, and several clinical factors [7]. Hyponatremia (serum sodium $\leq 135 \mathrm{mmol} / \mathrm{L}$ ) is independently associated with major complications, greater length of stay, higher hospital costs, and greater inpatient mortality in patients with suspected congestive heart failure [1] and with greater in-hospital and 60-day mortality in patients with heart failure [2]. It is an independent predictor of 30-day mortality in patients with acute ST-segment elevation myocardial infarction [3]. Given the preponderance of evidence suggesting that hyponatremia is an independent predictor of poorer outcomes, our findings suggest that the prognostic value of even severe hyponatremia may be underappreciated.

Another potential explanation for the low observed rates of coding is that hyponatremia, as identified by a single laboratory value, may have been a transient condition for some members. We analyzed single laboratory values and did not consider the results of prior or subsequent testing. Thus, it is possible that some members received follow-up testing that showed the condition to be resolved, thereby eliminating the need for documentation on the outpatient professional claim. Also, because the sample included commercially insured adults with relatively low amounts of comorbid illness, mildly decreased levels of serum sodium may not be clinically significant or require medical intervention. Nevertheless, we found sensitivity to be less than $30 \%$, even in the case of serum sodium $\leq$ $125 \mathrm{mmol} / \mathrm{L}$. Finally, because documentation of hyponatremia is unlikely to generate additional reimbursement for outpatient services, there may be little incentive for physicians to include it on the claim.

In contrast, the positive predictive value of outpatient claims for hyponatremia was also low (63\% for serum sodium $<136 \mathrm{mmol} / \mathrm{L}$ ). This finding may reflect the fact that hyponatremia is a chronic condition for some patients and is therefore likely to be noted on outpatient professional claims despite the fact that there are no observable laboratory claims within $+/-15$ days to support the diagnosis. The data used here, however, do not include sufficient detail to validate this hypothesis.

Although the impact of medications known to cause hyponatremia was not significant in the multivariable model, there was a trend toward less ICD-9-CM documentation of laboratory-identified hyponatremia in the presence of this factor. Outpatient claims for medications known to cause hyponatremia were observed within 60 days before through 15 days after 25\% of all laboratory claims indicating hyponatremia. This finding suggests that some clinicians may choose not to code hyponatremia when it may be the result of drug therapy. Other results of the multivariable model also suggest that ICD-9-CM coding of laboratory-identified hyponatremia may be especially poor for patients with peripheral vascular disease or diabetes. Claims for members with these conditions were more than $40 \%$ less likely to have an ICD-9-CM code for hyponatremia.

This study has some limitations. First, outpatient laboratory data are only available for approximately $10 \%$ of members in the IHCIS database. Second, the IHCIS database consists of managed care claims only and is therefore representative of an employer-based, commercially insured population. We expect that the elderly are significantly underrepresented in the database. Because the risk of hyponatremia is highest among the elderly and our results show that the frequency of coding for hyponatremia increases with age, our findings may not be generalizable to older populations. Inconsistent and inaccurate coding and the absence of clinical data regarding disease severity may have also affected our estimates. We required just 60 days of continuous coverage before and 15 days of coverage after the reference serum sodium date and searched for evidence of comorbidity claims within that time period only. Although this approach maximized our sample size, it also limited the available time frame in which we could observe comorbid illnesses, which may have led to an underestimation of these conditions in our analyses. We also chose to search for outpatient professional claims that were temporally adjacent to serum sodium laboratory tests (+/-15 days). As a result, the analysis is unable to capture instances where abnormal test results were addressed by providers without generation of an outpatient claim (eg, by phone or e-mail) or when a follow-up visit was performed outside of this time window. Finally, the study used outpatient clinical and laboratory information only. The results do not account for the possibility that a laboratory-identified diagnosis of hyponatremia, for example, may have been documented by an ICD-9-CM code on an inpatient claim just before or after the outpatient laboratory date. 


\section{Conclusion}

Our results suggest that the use of ICD-9-CM codes in administrative data alone is insufficient to identify hyponatremia in outpatient populations. Whenever possible, supplementary laboratory information should be used to help overcome this limitation of administrative claims.

\section{Abbreviations \\ CI: confidence interval; ICD-9-CM: International Classifica- tion of Diseases, Ninth Revision, Clinical Modification; IHCIS: Integrated Healthcare Information Services; OR: odds ratio.}

\section{Competing interests}

Ms Shea declares that she has no competing interests.

Dr Curtis reports receiving research and salary support from Allergan Pharmaceuticals, GlaxoSmithKline, Lilly, Medtronic, Novartis, Ortho Biotech, OSI Eyetech, Pfizer, and Sanofi-Aventis.

Dr Szczech reports receiving personal income for consulting from Sanofi-Aventis.

Dr Schulman reports receiving research and/or salary support from Actelion, Allergan, Amgen, Arthritis Foundation, Astellas Pharma, Bristol-Myers Squibb, The Duke Endowment, Genentech, Inspire Pharmaceuticals, Johnson \& Johnson, Kureha Corporation, LifeMasters Supported SelfCare, Medtronic, Merck, Nabi Biopharmaceuticals, National Patient Advocate Foundation, North Carolina Biotechnology Center, Novartis, OSI Eyetech, Pfizer, Roche, Sanofi-Aventis, Schering-Plough, Scios, Tengion, Theravance, Thomson Healthcare, Vertex Pharmaceuticals, Wyeth, and Yamanouchi USA Foundation; receiving personal income for consulting from Avalere Health, LifeMasters Supported SelfCare, McKinsey \& Company, and the National Pharmaceutical Council; having equity in and serving on the board of directors of Cancer Consultants; having equity in and serving on the executive board of Faculty Connection LLC; and having equity in Alnylam Pharmaceuticals.

\section{Authors' contributions}

AMS obtained the data, performed the statistical analysis, analyzed and interpreted the data, and drafted the manuscript. LHC conceived and designed the study, obtained the data, analyzed and interpreted the data, obtained funding, supervised the study, and revised the manuscript for important intellectual content. LAS provided expertise in nephrology, analyzed and interpreted the data, and revised the manuscript for important intellectual content. KAS conceived and designed the study, analyzed and interpreted the data, obtained funding, and revised the manuscript for important intellectual content. All authors read and approved the final manuscript.

\section{Acknowledgements \\ Funding/support}

This study was supported by Sanofi-Aventis. The sponsor had no role in the design and conduct of the study; the collection, management, analysis, or interpretation of the data; or the preparation of the manuscript. According to the terms of the research agreement, the sponsor had an opportunity to review a draft of the manuscript. The authors had full control over the preparation and approval of the manuscript and the decision to submit the manuscript for publication.

\section{Additional contributions}

We thank Damon Seils of Duke University for editorial assistance and manuscript preparation. Mr Seils did not receive compensation for his assistance apart from his employment at the institution where the study was conducted.

\section{References}

I. Chin MH, Goldman L: Correlates of major complications or death in patients admitted to the hospital with congestive heart failure. Arch Intern Med 1996, I56:I8I4-I820.

2. Klein L, O'Connor CM, Leimberger JD, Gattis-Stough W, Pina IL, Felker GM, Adams KF Jr., Califf RM, Gheorghiade M: Lower serum sodium is associated with increased short-term mortality in hospitalized patients with worsening heart failure: results from the Outcomes of a Prospective Trial of Intravenous Milrinone for Exacerbations of Chronic Heart Failure (OPTIME-CHF) study. Circulation 2005, I I I:2454-2460.

3. Goldberg A, Hammerman H, Petcherski S, Zdorovyak A, Yalonetsky S, Kapeliovich M, Agmon Y, Markiewicz W, Aronson D: Prognostic importance of hyponatremia in acute ST-elevation myocardial infarction. Am J Med 2004, I I 7:242-248.

4. Goldberg A, Hammerman H, Petcherski S, Nassar M, Zdorovyak A, Yalonetsky S, Kapeliovich M, Agmon Y, Beyar R, Markiewicz W, Aronson D: Hyponatremia and long-term mortality in survivors of acute ST-elevation myocardial infarction. Arch Intern Med 2006, 166:78I-786.

5. Borroni G, Maggi A, Sangiovanni A, Cazzaniga M, Salerno F: Clinical relevance of hyponatraemia for the hospital outcome of cirrhotic patients. Dig Liver Dis 2000, 32:605-610.

6. Londono MC, Guevara M, Rimola A, Navasa M, Taura P, Mas A, Garcia-Valdecasas JC, Arroyo V, Gines P: Hyponatremia impairs early posttransplantation outcome in patients with cirrhosis undergoing liver transplantation. Gastroenterology 2006, 130:1 I35-1143.

7. Terzian C, Frye EB, Piotrowski ZH: Admission hyponatremia in the elderly: factors influencing prognosis. J Gen Intern Med 1994, 9:89-91.

8. Anderson RJ, Chung HM, Kluge R, Schrier RW: Hyponatremia: a prospective analysis of its epidemiology and the pathogenetic role of vasopressin. Ann Intern Med 1985, 102: I64-168.

9. Gross P: Correction of hyponatremia. Semin Nephrol 200I, 21:269-272.

10. Miller M, Morley JE, Rubenstein LZ: Hyponatremia in a nursing home population. J Am Geriatr Soc 1995, 43: 1410-14I3.

II. DeVita MV, Gardenswartz MH, Konecky A, Zabetakis PM: Incidence and etiology of hyponatremia in an intensive care unit. Clin Nephrol 1990, 34:163-166.

12. Asch SM, Sloss EM, Hogan C, Brook RH, Kravitz RL: Measuring underuse of necessary care among elderly Medicare beneficiaries using inpatient and outpatient claims. JAMA 2000, 284:2325-2333

13. Bradley EH, Herrin J, Elbel B, McNamara RL, Magid DJ, Nallamothu BK, Wang Y, Normand SL, Spertus JA, Krumholz HM: Hospital quality for acute myocardial infarction: correlation among process measures and relationship with short-term mortality. JAMA 2006, 296:72-78. 
14. Encinosa WE, Bernard DM, Chen CC, Steiner CA: Healthcare utilization and outcomes after bariatric surgery. Med Care 2006, 44:706-7I2.

15. Hassett MJ, O'Malley AJ, Pakes JR, Newhouse JP, Earle CC: Frequency and cost of chemotherapy-related serious adverse effects in a population sample of women with breast cancer. J Natl Cancer Inst 2006, 98: I 108-I I I7.

16. Krumholz HM, Wang Y, Mattera JA, Wang Y, Han LF, Ingber MJ, Roman S, Normand SL: An administrative claims model suitable for profiling hospital performance based on 30-day mortality rates among patients with heart failure. Circulation 2006, II3:1693-170I.

17. Pine M, Jordan HS, Elixhauser A, Fry DE, Hoaglin DC, Jones B, Meimban R, Warner D, Gonzales J: Enhancement of claims data to improve risk adjustment of hospital mortality. JAMA 2007, 297:7I-76.

18. Tang PC, Ralston M, Arrigotti MF, Qureshi L, Graham J: Comparison of methodologies for calculating quality measures based on administrative data versus clinical data from an electronic health record system: implications for performance measures. J Am Med Inform Assoc 2007, I4:10-15.

19. Werner RM, Bradlow ET: Relationship between Medicare's hospital compare performance measures and mortality rates. JAMA 2006, 296:2694-2702

20. Jollis JG, Ancukiewicz M, DeLong ER, Pryor DB, Muhlbaier LH, Mark DB: Discordance of databases designed for claims payment versus clinical information systems. Implications for outcomes research. Ann Intern Med 1993, I I 9:844-850.

21. McCarthy EP, lezzoni LI, Davis RB, Palmer RH, Cahalane M, Hame MB, Mukamal K, Phillips RS, Davies DT Jr.: Does clinical evidence support ICD-9-CM diagnosis coding of complications? Med Care 2000, 38:868-876.

22. Romano PS, Chan BK, Schembri ME, Rainwater JA: Can administrative data be used to compare postoperative complication rates across hospitals? Med Care 2002, 40:856-867.

23. Romano PS, Schembri ME, Rainwater JA: Can administrative data be used to ascertain clinically significant postoperative complications? Am J Med Qual 2002, I 7: I45-I54.

24. Solberg LI, Engebretson KI, Sperl-Hillen JM, Hroscikoski MC, O'Connor PJ: Are claims data accurate enough to identify patients for performance measures or quality improvement? The case of diabetes, heart disease, and depression. Am J Med Qual 2006, 21:238-245.

25. Quan H, Parsons GA, Ghali WA: Validity of procedure codes in International Classification of Diseases, 9th revision, clinical modification administrative data. Med Care 2004, 42:80I-809.

26. Geraci JM, Ashton CM, Kuykendall DH, Johnson ML, Wu L: International Classification of Diseases, 9th Revision, Clinical Modification codes in discharge abstracts are poor measures of complication occurrence in medical inpatients. Med Care 1997, 35:589-602

27. Wei F, Walsh CM: Validation of data collection for the HEDIS performance measure on chlamydia screening in an MCO. Am J Manag Care 2003, 9:585-593.

28. Harrold LR, Saag KG, Yood RA, Mikuls TR, Andrade SE, Fouayzi $H$, Davis J, Chan KA, Raebel MA, Von Worley A, Platt R: Validity of gout diagnoses in administrative data. Arthritis Rheum 2007, 57:103-108.

29. Movig KL, Leufkens HG, Lenderink AW, Egberts AC: Validity of hospital discharge International Classification of Diseases (ICD) codes for identifying patients with hyponatremia. J Clin Epidemiol 2003, 56:530-535.

30. Katz MA: Hyperglycemia-induced hyponatremia--calculation of expected serum sodium depression. N Engl J Med I973, 289:843-844.

31. Birman-Deych E, Waterman AD, Yan Y, Nilasena DS, Radford MJ, Gage BF: Accuracy of ICD-9-CM codes for identifying cardiovascular and stroke risk factors. Med Care 2005, 43:480-485.

32. Quan H, Sundararajan V, Halfon P, Fong A, Burnand B, Luthi JC, Saunders LD, Beck CA, Feasby TE, Ghali WA: Coding algorithms for defining comorbidities in ICD-9-CM and ICD-10 administrative data. Med Care 2005, 43:1 I30-II39.

33. Adrogue $\mathrm{HJ}$ : Consequences of inadequate management of hyponatremia. Am J Nephrol 2005, 25:240-249.
34. De LL, Klein L, Udelson JE, Orlandi C, Sardella G, Fedele F, Gheorghiade M: Hyponatremia in patients with heart failure. Am J Cardiol 2005, 96: I 9L-23L.

35. Adrogue HJ, Madias NE: Hyponatremia. N Engl J Med 2000, 342: $1581-1589$

36. 2006 Professional ICD-9-CM for Hospitals-Volumes I, 2, and 3 6th edition. Edited by: Hart AC, Hopkins CA and Ford B. Salt Lake City, Utah, Ingenix; 2005

37. Fraser JF, Stieg PE: Hyponatremia in the neurosurgical patient: epidemiology, pathophysiology, diagnosis, and management. Neurosurgery 2006, 59:222-229.

38. Renneboog B, Musch W, Vandemergel X, Manto MU, Decaux G: Mild chronic hyponatremia is associated with falls, unsteadiness, and attention deficits. Am J Med 2006, I I 9:7I-78.

39. Wu CC, Yeung LK, Tsai WS, Tseng CF, Chu P, Huang TY, Lin YF, Lu $\mathrm{KC}$ : Incidence and factors predictive of acute renal failure in patients with advanced liver cirrhosis. Clin Nephrol 2006, 65:28-33.

\section{Pre-publication history}

The pre-publication history for this paper can be accessed here:

http://www.biomedcentral.com/1471-2369/9/5/prepub
Publish with Bio Med Central and every scientist can read your work free of charge

"BioMed Central will be the most significant development for disseminating the results of biomedical research in our lifetime. "

Sir Paul Nurse, Cancer Research UK

Your research papers will be:

- available free of charge to the entire biomedical community

- peer reviewed and published immediately upon acceptance

- cited in PubMed and archived on PubMed Central

- yours - you keep the copyright 